\title{
Computer Entertainment Technologies for the Visually Impaired: An Overview
}

\author{
Manuel López Ibáñez, Alejandro Romero-Hernández, Borja Manero, María Guijarro * \\ Complutense University, Madrid (Spain)
}

Received 17 October 2020 | Accepted 18 March 2021 | Published 23 April 2021

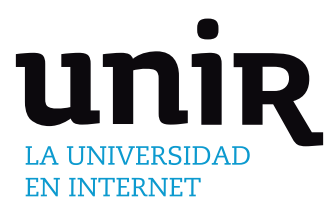

\section{ABSTRACT}

Over the last years, works related to accessible technologies have increased both in number and in quality. This work presents a series of articles which explore different trends in the field of accessible video games for the blind or visually impaired. Reviewed articles are distributed in four categories covering the following subjects: (1) video game design and architecture, (2) video game adaptations, (3) accessible games as learning tools or treatments and (4) navigation and interaction in virtual environments. Current trends in accessible game design are also analysed, and data is presented regarding keyword use and thematic evolution over time. As a conclusion, a relative stagnation in the field of human-computer interaction for the blind is detected. However, as the video game industry is becoming increasingly interested in accessibility, new research opportunities are starting to appear.

\section{KEYWORDS}

Accessibility, Computer Entertainment, Humancomputer Interaction, Video Games, Visual Impairments.

DOI: $10.9781 /$ ijimai.2021.04.008

\section{INTRODUCTION}

$\mathrm{T}$ HROUghout the last decades, accessibility in interactive applications has been profoundly improved, especially when it comes to dealing with the experiences of blind and visually impaired people while performing everyday tasks. For example, screen readers [1]-[4] have greatly eased the process of interacting with computers, and nowadays, capable digital assistants abound [5]-[7], making simple, day-to-day interactions more accessible than ever for people with visual impairments, even though there is still much room for improvement in this area [8], [9].

However, entertainment technologies, and particularly video games, are still primarily visual, and often disregard the importance of universal access in this context. Even so, recent advancements, such as the notably deep accessibility measures that players can find in The Last of Us: Part II [10], have gathered a considerable amount of attention and praise from both users and the media. Adaptations of this quality are still difficult to achieve, however, as most companies will not allocate enough resources to cover the needs of a relatively small portion of their clients. This is the reason why research in the field of accessibility for the blind and visually impaired revolving around computer entertainment is still relatively scarce, but necessary in order to achieve much more welcoming virtual environments for everyone.

The goals of this article are two: on one hand, to thoroughly describe the state of the art in the field of accessibility for the blind or visually impaired; on the other, to detect trends in this area of knowledge.

* Corresponding author.

E-mail addresses: manuel.lopez.ibanez@ucm.es (M. López Ibáñez), alerom02@ucm.es (A. Romero-Hernández), bmanero@ucm.es (B.Manero), mguijarro@ucm.es (M. Guijarro).

\section{Research Methodology}

\section{A. Search Terms}

In order to collect relevant publications in this field, we combined the following search terms or expressions: "blind", "visually impaired", "visual impairment", "accessibility", "accessible technologies", "disability", "video games", "audio games" and "computer entertainment". These were used in Google Scholar, IEEE Xplore and ACM Digital Library, and results were limited to articles published from 1993 to 2020. A total of 102 articles were selected throughout this process, by considering their relevance to the subject. Due to the relatively small number of publications available in this area, articles were only rejected when their focus was not accessible video and audio games, or simply when they did not appear in any search engine after inputting the alreadymentioned search terms.

\section{B. Categorisation}

As a means to classify all selected works, we started a preliminary review which consisted of reading their abstracts and keywords. After this, four general categories were created, and articles were distributed between them as Table I shows.

Thematic connections between articles were also explored during the classification process. Fig. 1 focuses on the distribution of each article according to this taxonomy. Coloured entries evince a relevant relationship between an article and a different category marked with the same colour; each of these articles still pertain to their main categories, but include references to subjects or methods present in a different one. Subcategories have also been included, in order to reach more precision regarding thematic classification.

\section{Contributions}

As a second step, articles were read and analysed one by one in order to fully understand their content, while extracting metrics from them. 


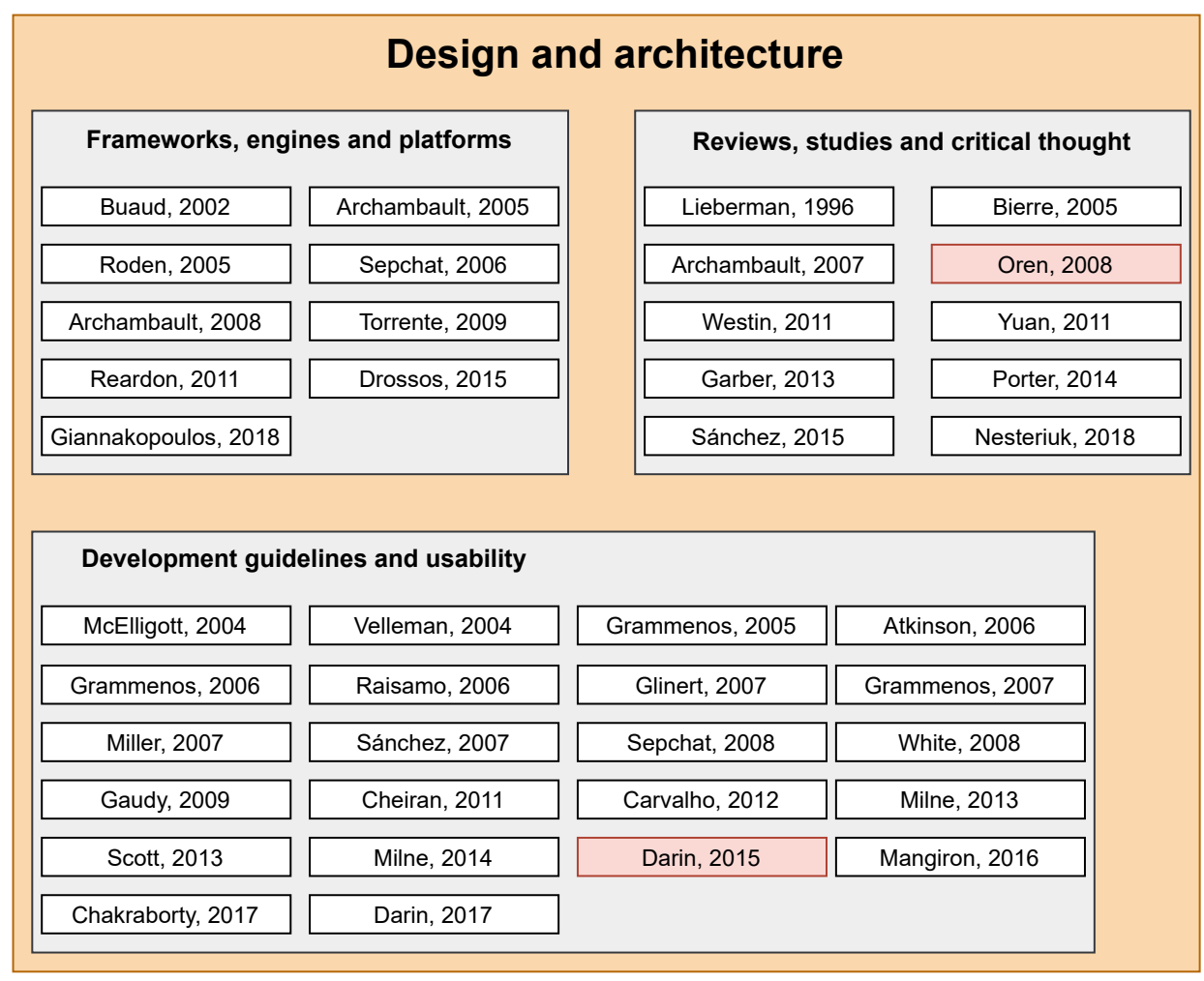

\section{Adapting games}

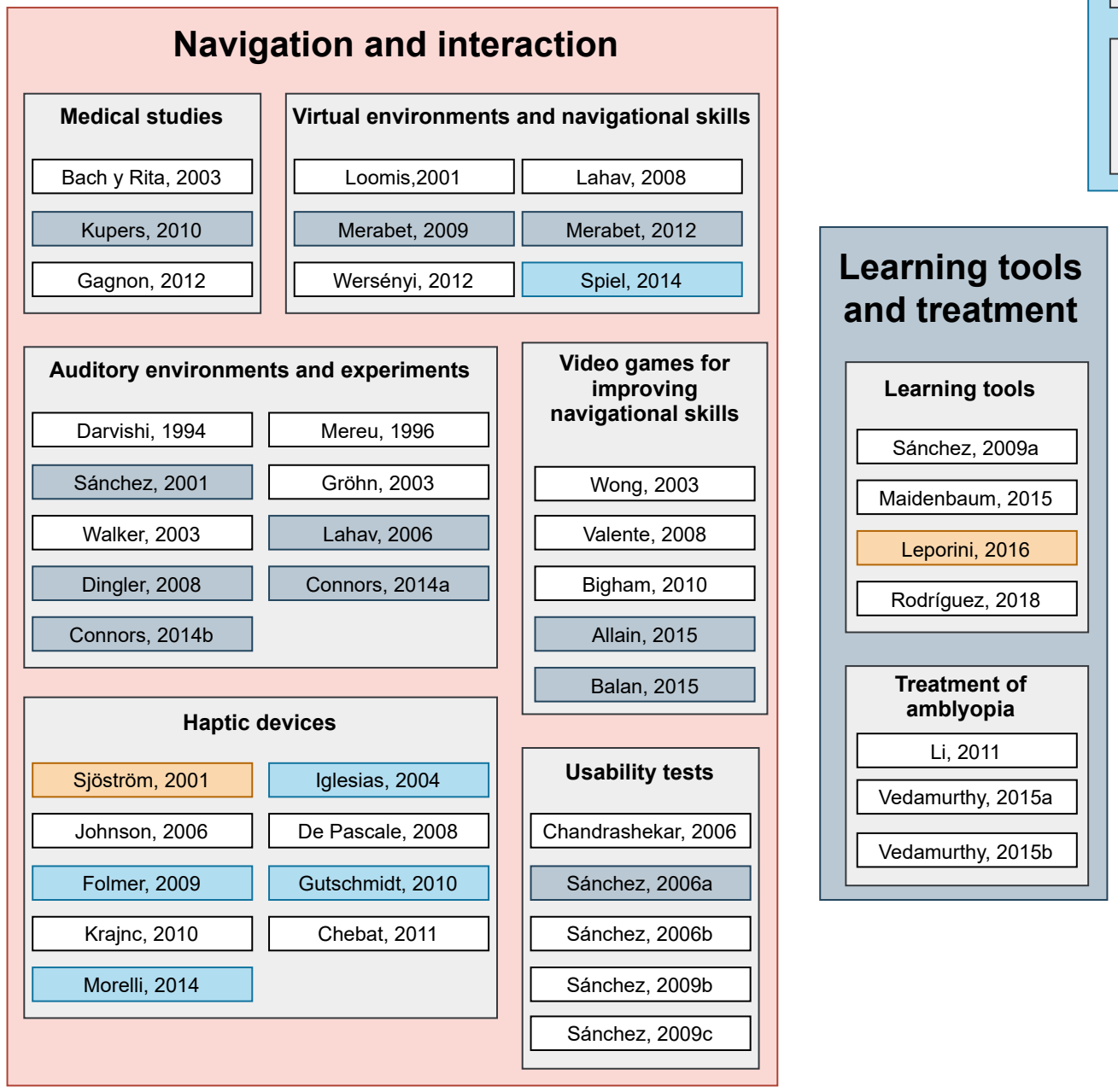

Fig. 1. Article classification depending on subject. Coloured references mean there is a significant relationship between said reference and another, secondary category, marked with that same colour. 


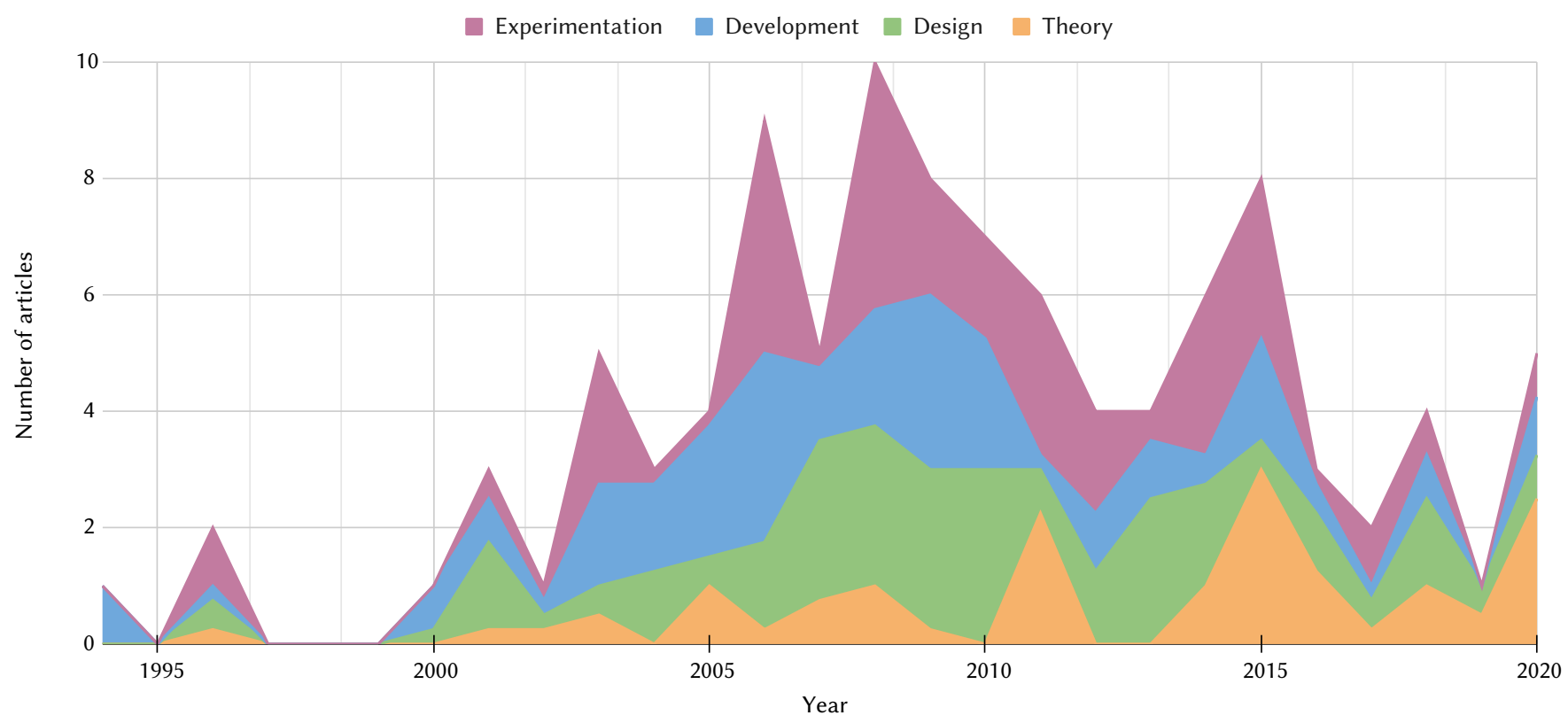

Fig. 2. Evolution of research approaches, in terms of relevant contributions, over time.

A survey was carried out to categorise the types of contributions made by each of them. To do this, we selected the four main contributions we were looking for in our analysis: 1) a theoretical contribution to the field, 2) the design of a tool, 3) the development of a tool, or 4) the development of an experimental study.

Then, we developed a system which allowed for assigning a numerical array score to every article depending on its contributions. A number between 0 and 1 was assigned to every mentioned contribution type so that every article's aggregated value was always exactly 1 . Each category could have 5 different values: $0,0.25,0.5,0.75$ and 1 . Valid distributions would be, for example: $[0,0.25,0.75,0]$ or $[1,0,0,0]$ The results of this analysis can be appreciated in Table II, where both the number of articles and their distribution in terms of contribution types are represented.

TABLE I. Number of ENTRIES IN EAch CATEgory

\begin{tabular}{lc}
\hline Category & Number of articles \\
\hline $\begin{array}{l}\text { Design and architecture of video games for blind } \\
\text { or visually impaired players }\end{array}$ & 43 \\
\hline \begin{tabular}{l} 
Adapting games for the visually impaired \\
\hline $\begin{array}{l}\text { Video games as a learning tool or as treatment } \\
\text { for people with visual impairments }\end{array}$
\end{tabular} \\
\hline $\begin{array}{l}\text { Navigation and interaction of visually impaired } \\
\text { players in virtual environments }\end{array}$ & 37 \\
\hline TOTAL & $\mathbf{1 0 2}$ \\
\hline
\end{tabular}

Fig. 2 represents the research trends (experimentation, development, design, and theory) over the years. 66 papers present a tool design process, 61 delve into development, and 65 include experiments. However, only 21 articles offer a theoretical contribution.

\section{Summaries}

Lastly, contributions were summarised and explained in Sections III to VI.

Section III contains references to specific video games, design aids or software architectures designed with accessibility in mind, and focuses on final products, coming from both academic and industrial environments. Some of these games and interactive applications solve specific problems detailed in different sections, but were kept in this category due to them being final products or systems aimed towards facilitating the design of accessible video games. Systematic reviews or compilations addressing the design and architecture of accessible games are also included in this category.

Section IV delves into how non-accessible video games can be adapted to become usable by blind or visually impaired players. This is a narrow field, as it is generally considered suboptimal to adapt already-existent games instead of creating them from scratch with accessibility in mind. However, some of the ideas presented in this section are very interesting, and can be applied to the field of accessible game design.

Section V captures a new trend in this field: designing serious games as learning tools or as a treatment for the blind or visually impaired. This category includes both medical and educational applications, and presents technologies which could be applied to the design of accessible serious games.

Lastly, section VI covers the development of technologies aimed towards improving non-visual navigation and human-computer interaction in virtual environments. This field relies largely upon haptic or auditory user interfaces, some of which have already been integrated in accessible video games with positive results. This category also summarises different experiments carried out to test the effectiveness of a variety of tools created either to improve navigational skills or to determine how accessible an application or content is. This section also contains some studies about the effect of navigating virtual environments in the brain of non-sighted users.

\section{Design And Architecture of Video Games for Blind or Visually Impaired Players}

Most articles reviewed during this research process address everyday problems associated with developing accessible video games for the blind or visually impaired. For example, Archambault [11] proposes a game platform, named Blindstation, useful for solving technical problems revolving around accessibility and interactive experiences. Several games are presented, adapted and evaluated by blind children, and the conclusion is that these games constitute more than accessible applications, and can be considered a valid entertainment product by users. 
Table II. Number of Research Articles per Type of Contribution. One Article May Appear in More Than One Category

\begin{tabular}{|c|c|c|c|c|}
\hline Category & Theory & Design & Development & Experimentation \\
\hline Design and architecture of video games for blind or visually impaired players & 15 & 28 & 24 & 19 \\
\hline Adapting games for the visually impaired & 2 & 12 & 11 & 10 \\
\hline $\begin{array}{l}\text { Video games as a learning tool or as treatment for people with visual } \\
\text { impairments }\end{array}$ & 3 & 3 & 4 & 7 \\
\hline $\begin{array}{l}\text { Navigation and interaction of visually impaired players in virtual } \\
\text { environments }\end{array}$ & 6 & 23 & 22 & 29 \\
\hline TOTAL & 26 & 66 & 61 & 65 \\
\hline
\end{tabular}

After his previous contribution, the same author [12] delves on the very idea of game accessibility through a systematic review. Academic articles published in the last decade are taken into consideration. Besides, an architecture for a framework allowing mainstream game accessibility is also included.

Eventually, this author produced an accessibility framework [13] allowing game developers to design accessible games, as well as assistive game interfaces.

The TiM project [14] presents a similar approach, in order to facilitate the development of accessible games. This project has helped design and adapt computer games for children with visual disabilities. A software architecture is defined, containing a proposed interaction design based on common auditory and tactile resources.

On the other hand, Roden and Parberry [15] describe a framework for designing 3D audio games aimed at wider markets, instead of exclusively made for the blind. The system is able to represent the world in a very simple and restrictive manner, so that players know exactly where they are at all times. Instead of using true 3D audio, the authors propose a 2D virtual stage which can support surround sound configurations of up to 6 speakers (5.1), but does not take into account sound source height.

The AGRIP project [16] focuses on the creation of modern firstperson shooter games which are accessible to the blind and visuallyimpaired. As a result, the low quality of the accessibility infrastructure utilised in the video game AudioQuake is exposed. The use of this technology in educational settings is also criticised.

Reardon [17] presents a technology called AbES (Audio-Based Environment Simulator), which acts as a navigation aid for the blind. The idea behind the system is to help non-sighted individuals to learn routes and "paint" navigation maps in a similar way sighted people do. This kind of technology has been used to map real environments, such as a university campus or an underground station.

By now, it should be clear that options for blind people are scarce in the world of interactive entertainment. Thus, Carvalho, Guerreiro, Duarte et. al. [18] present an iterative and participatory design of an audio-based puzzle game, along with a preliminary evaluation with 13 blind participants. The outstanding results achieved highlight that the game is both fun and challenging for its target audience.

Another article by Bierre, Chetwynd, Ellis et al. [19] proposes a study about different commercial video games which implement accessibility. The authors conclude that there exists a clear need for accessibility in commercial games.

Velleman, Van Toi, Huiberts et al. [20] introduce a series of video games specifically made for the blind, as a result of a collaboration between the Utrecht School of the Arts and the Bartiméus Accessibility Foundation. These games include Drive, The Curb Game, Hall of Sound, Powerchords, Wow and Demor, among other titles. A detailed explanation is given on the design principles followed by each project, as well as their goals.
White, Fitzpatrick and McAllister [21] face the issues of navigation and feedback in 3D environments for the visually impaired by interviewing 8 expert users and letting them guide design proposals. The study is focused on multi-user virtual environments, and particularly on Second Life, a persistent virtual world. Multimodal approaches, including audio and haptics, are suggested as a solution for most accessibility issues in video games.

Defining non-functional software requirements is a critical task for the success of any information system. In the field of accessibility and usability, non-functional requirements are considered especially important when developing information systems. The work presented in [22] aims to better understand the non-functional software requirements needed to address accessibility and usability challenges for people with visual disabilities in video games. To achieve this, a study of the different analysis, results and recommendations derived from previous studies is detailed. Starting from a 2D arcade video game from the 1980s, these authors develop a new version where they incorporate hardware controls and sound effects, making it possible for people with visual disabilities to use it. Through interviews with six visually impaired users, they also determine that the experience with this new version is positive.

Sepchat, Monmarché, Slimane et al. [23] claim that the main senses involved in making a video game accessible for the blind are hearing and touch, and present a semi-automatic system which can help developers design accessible games controlled by tactile surfaces and described through audio. All of these games must be based on a $2 \mathrm{D}$ grid over which a character moves. Two examples are included: a maze game, in which the player has to find an exit while avoiding obstacles and enemies, and a snake game, in which the player is a snake that grows by eating apples and dies when hitting a wall or its own tail.

By considering the impact on human development that video games have, this work [24] proposes a 3D game that is based on the perception of sound and haptic feedback, leaving aside any visual interaction. This game has been tested with blind and blindfolded people, thus highlighting several interaction problems which needed to be solved. The software was then redesigned by taking into account these results.

A video game and a functional game engine aimed at children with visual disabilities are presented in [25]. On one hand, the game is implemented using binaural technology that allows players to listen and navigate through the game space by adding location information to audio. On the other hand, the engine presented by these authors enables a quick game development process for people with visual disabilities, this contribution being a good starting point for future developments in the field.

Gaudy, Natkin and Archambault [26] present the design of an audio game in which interaction is based on very simple actions, so that no instructions are needed before starting to play. Users are not supposed to fully understand all game mechanics from the beginning, though. Instead, they discover the intricacies of gameplay as the game 
progresses. An experiment aimed towards a usability validation is also presented in this article. Its results indicate that, even though all players managed to progress in the game, not everyone understood how specific mechanics worked.

Other authors [27] present a different approach for developing video games which are universally accessible. This way, people with visual and hearing impairments, multiple variants of color-blindness and reduced vision problems can be able to play and learn through them. These same authors also carried out simulation tests to prove the functionality of this perspective.

A set of inclusive and accessible games are presented in [28]. In all of these, accessibility is achieved through auditory representations of virtual environments. A development platform, named Memor-i studio, is also presented. It allows non-technical users (including blind people under supervision) to create inclusive games. Both the games and the platform have been tested by blind or visually impaired users with positive results.

AudiOdyssey, a video game prototype designed to be used by both sighted and visually impaired people, is presented in [29]. Said prototype is a rhythm-based game with fully accessible menus and game levels. It also allows for a variety of control schemes, so that it can adapt to every type of player.

Another research [30] describes the user interface design for the accessible and multiplayer game Access Invaders. This game simultaneously adapts to the needs of different player types by defining parallel game universes, thus allowing visually impaired people to play simultaneously with other users.

Sánchez and Hassler [31] build a virtual environment that contains a navigation aid for the blind and does not rely on 3D audio to function. Instead, these authors propose a system called AudioMUD, which uses spoken text as the only way to describe both virtual environments and player interactions. The system was evaluated through a cognitive testing process, concluding that collaboration skills and leadership can be developed while playing with this kind of technology.

UA-Chess, a fully accessible chess game which can be played through a standard web browser, is presented in [32]. Its main feature is its accessible nature: it can be played simultaneously by people with different disabilities, including visual impairments. Finally, this research analyzes how accessibility is supported in UA-Chess for different categories of users through its graphical user interface, its adaptiveness and the variety of input and output modes.

VBGhost [33] is presented as an educational, multiplayer game for blind or visually impaired people, which reinforces concepts related to reading and writing in Braille. Its main contribution to the field of game development is its interface, which uses six touch areas with a circular shape, enabling players to easily input letters in Braille.

These same authors [34] propose a compilation of their accessible and educational games, called BraillePlay, which includes four different titles: VBReader, VBWriter, VBHangman and the already-mentioned $V B G h o s t$. A formal evaluation of said games is also included, focusing on accessibility, engagement and effectiveness. The results show that engagement is the only issue when trying to get children to interact with these games for a period of time longer than four weeks.

Torrente, Del Blanco, Moreno-Ger et al. [35] present accessibility as a means to maintain inclusivity in e-learning processes. They review a variety of methodologies, tools and design patterns for accessible video games, and propose a series of guidelines for designing inclusive games for e-learning. A platform called <e-Adventure> is also presented, focusing on the generation of point-and-click adventure games. It contains a game authoring editor and a game engine. The article also concludes that accessibility is an often overlooked matter in the game development business, and that there is a need for tools which make adapting games to everyone easier and less expensive for professional game developers.

Other authors [36] present audio games as a low-cost alternative to portable video games for visually impaired players. An accessible sudoku game is described and implemented through RockBox, a custom firmware for popular MP3 players. Even though this article was written just before the popularization of smartphone games, it predicts the impact they would have in blind players.

McElligott and Van Leeuwen [37] propose a methodology for designing toys and computer games for the blind which involves taking into account their abilities, instead of their disabilities. Three different scenarios are provided as examples of inclusive design, and all of them are validated through experiments with small children. After these validation sessions, the authors conclude there is a need for more varied and balanced sensory stimulation in games for visually impaired children. Thus, video games that only use auditory stimuli have room for improvement if other communication channels are used, such as tactile surfaces.

Nesteriuk [38] defends the importance of audio games for general accessibility, and explains how they can help visually impaired people stay connected in a digital world. A survey about current advancements in the field is the main contribution of this author's work; however, he also introduces a series of design guidelines for accessibility in video games, based on the reviewed literature.

In a first approach towards improving game-related skills in people with visual disabilities, Darin [39] proposes a methodology to evaluate usability and cognitive impact in multimodal video games. This work is concluded with a list of guidelines for the design of interface elements.

Through further research, the same author [40] presents guidelines for the evaluation of usability in audio-based and haptic video games for blind people. A guide is also included, based on the comparison of usability evaluation methods (EMU) in this context, as well as an analysis on the evaluation of audio as a mode of interaction.

Grammenos, Savidis and Stephanidis [41] also describe the basic steps to adapt and apply a unified design method in the development of accessible video games. Key differences between turn-based strategy game design and action games are outlined.

Scott and Ghinea [42] describe the result of providing a list of accessibility guidelines to the participants at the Global Game Jam (GGJ), an event where small games are made in only a 48-hour development cycle. The authors conclude that designing games with accessibility in mind is possible even in a short time-frame, and that events like the GGJ can raise awareness about these issues among game developers.

Leporini and her colleagues explored another example of the potential use of serious games in rehabilitation in [43], with a particular focus on skills and retraining for blind and partially sighted people. The authors present a theoretical framework for developing this type of video games, and propose some design guidelines to follow when using these games in rehabilitation scenarios.

Lieberman [44] writes an article in an attempt to motivate our society to design universally accessible activities and video games.

Another article [45] analyses the current state of game accessibility, with a particular focus on the blind and visually impaired. They also discuss the barriers these groups face, as well as their options in the video game industry, such as audio games and "video-less" games. They conclude by suggesting the application of audio description techniques to video games, which could potentially improve accessibility.

Miller, Parecki and Douglas [46] provide a formal description of an auditory game specifically designed for blind people. The game 
requires players to match a rhythm with keystroke patterns, and includes an audio-based menu and a data collection tool that allows for gameplay analysis. This kind of software can also be used as an experimental tool for studying how blind players behave in a virtual auditory environment, and provides an unbiased performance variable (called "score"), which can potentially prove useful when judging the utility of certain game design decisions.

Oren, Harding and Bonebright [47] analyse and compare mental images created by both sighted and non-sighted players of a 2D, sidescrolling audio game. User descriptions of the virtual environment were retrieved and transferred to a map, and they were assigned a "mapping score" by judging how closely this mental image resembled the actual layout of the game. The authors conclude that there is not a significant difference in accuracy of mental maps created by sighted and visually impaired players, and that audio can convey enough information to allow for accurate virtual environment representation in video games.

Porter [48] takes into account mainstream gaming when addressing accessibility issues present in interactive software. He outlines a future research plan focusing on working together with actual game developers in order to improve how commercial products are accessed by people with disabilities.

Raisamo, Hippula, Patomaki et al. [49] describe how several haptic devices were used to generate feedback in multimodal applications. A method to conduct usability testing with visually impaired children is also explained.

Garber [50] presents a study where the need to make video games accessible is highlighted. To achieve this, a review of academic literature is included, pointing out the benefits and barriers found in software design, and concluding that the current trend is to include some sort of accessibility measure in new developments.

Sánchez, Darin and Andrade [51] conduct a systematic review of multimodal games which concludes that audio is a very common interface element, but other communication channels remain underused. For example: adaptation of GUI element sizes or the use of colours which are discernible by colour-blind people are uncommon practices in video game design. Besides, most games in this review do not take cognitive impact into account, and this approach would be needed for the development of cognitive skills in players who are blind.

A systematic review by Westin, Bierre, Gramenos et al. [52] covers general progress in the field of game accessibility from 2005 to 2010. Visual impairments prove to be the most researched topic in this context. The authors propose exploring more ways of employing haptics or tactile interfaces as an addition to audio in video games for the blind, which is still a very relevant topic for current research. Another survey about general game accessibility [53] defines visually impaired players as "unable to perceive primary stimuli", and propose modifying essential communication elements as the only way to improve video games on this matter. The most common adaptation techniques observed in reviewed literature are replacing visuals with audio or haptic feedback, and enhancing visuals for players with partial eyesight.

Lastly, Brown and Anderson [54] also evaluate the current state of accessibility in video games, specifically in terms of designing for disability. They evaluate 50 games, chosen using objective criteria, such as total sales, critical reception, awards, etc., in order to examine the widest possible sample of the most prominent games released in 2019. The results highlight design pitfalls and innovations regarding accessibility in four key areas: audio, vision, player movement and difficulty.
IV. Adapting Games for the Visually Impaired

Other authors, however, explore ways to adapt already existent video games in order to make them more accessible, and audio plays a very important role in this process. The subject of how audio can be used to make games accessible is explored by [55]. These researchers add sound to a shooting game with audio aids in order to provide information about direction and distance of moving targets, and then test it with users. The result is that both blind and sighted players can play this kind of game, and that sighted people also improve their performance with the help of audio.

An interactive, audio-based virtual environment called AudioBattleShip is presented in another research article by Sánchez, Baloian, Hassler et al. [56]. It aims to enhance collaboration and cognition in blind learners, and focuses on using spatialized sound to develop collaborative skills in blind learners.

[57] introduces the Racing Auditory Display (RAD), an audio-based user interface that allows players who are blind to play the same kind of racing games that sighted players can play with a similar efficiency and sense of control. Thanks to 2 empirical studies, these researchers find that players preferred the RAD's interface over that of Mach 1, a popular blind-accessible racing game.

Another research by [58] results in the game Audio Space Invaders. This software focuses on demonstrating how a traditional space invasion game can be made accessible using a 3D audio (Ambisonics) environment. The authors also present a multimodal game where sighted and blind users can share a gameplay experience by combining audio and visual interfaces with force feedback joystick movement.

Rock Band is a commercial video game which combines audio with sensors. The work by [59] presents a modification called Rock Vibe, which allows to create visual representations using haptic and audio feedback, thus granting access to this game for visually impaired people. A usability evaluation of this project is also included.

Through two exergames (Dance Revolution Extreme 2 and EyeToy Kinetic), Gasperetti et. al. [60] present a list of modifications to be added in order to make a game accessible to visually impaired users.

A similar approach is taken by [61], who propose a badminton game called Sonic-Badminton, in which users can practice this sport by means of a virtual shuttlecock, using audio cues as navigational references. To verify its usability, the authors present a study carried out on both blind and sighted users, and state that all participants were able to play and enjoyed the game.

$V I$ Tennis is another exergame presented by [62]. It is a modified version of a popular motion sensing game that explores the use of vibrotactile and audio cues. This application was tested by 13 blind children and the authors were able to observe how they improved their physical activity.

These same authors present, in another article [63], an adaptation of VI Bowling, a haptic and auditory exergame which can be played using a motion detection controller. This software makes use of a novel technique to perform sensory-motor space challenges, which can be applied to motor learning. VI Bowling was evaluated by six blind adults, obtaining very positive results.

Another research by Vickers, Istance and Heron [64] aims towards a comprehensive software framework which allows for dynamic adaptation of computer games to different levels of physical and cognitive abilities. The authors describe the principles by which games can be adapted, both during construction and during gameplay, in order to accommodate different abilities and disabilities, all while using the Game Accessibility Development Framework. 
Khaliq and Torre [65] also aim for a comprehensive approach, and study how to include accessibility in games for people with visual impairments in a variety of ways. They carry out a study on current technologies, and offer three general adaptation techniques, classified into visual, auditory and tactile. These approaches are justified with the results of experiments conducted on different groups of the visually impaired population.

Olsson [66], on the other hand, proposes a study about the different barriers to accessibility still existing in video games. In order to do so, a heuristic tool aimed towards accessibility evaluation is presented. The tool was validated by applying it to four different games. This research also explores the possibility of incorporating the tool into a game development process. The results constitute a relevant contribution about systematic examination of accessibility features and problems experienced in shooter games by disabled people.

Lastly, visual replacement is explored by [67] in an article that proposes replacing visual stimuli with haptic stimuli as a viable strategy to make Guitar Hero, a popular rhythm game, accessible. The authors call this new approach Blind Hero, and present a haptic glove which translates visual stimuli into haptic stimuli. They also conduct a study with this modified video game involving sighted and non-sighted players, as well as performance measurements and comparisons in order to decide if players get a similar gameplay experience. The results indicate that the haptic glove can successfully translate visual stimuli into haptic stimuli despite having to compromise some elements of gameplay. Except for these compromises, all participants considered playing Blind Hero a fun and enjoyable experience.

\section{Video Games as a Learning Tool or as Treatment} for People With Visual Impairments

In the reviewed literature, several researchers have spoken about how technology can improve people's lives with amblyopia. As an example, [68] present an experiment to determine whether playing video games can induce plasticity in the visual system of adults with amblyopia. Researchers divided 20 participants into three groups depending on the content they played: an action video game, a nonaction video game, and a crossover control group. Results showed that playing video games (both action and non-action games) for a short period using the amblyopic eye results in a substantial improvement in various fundamental visual functions. Finally, they claimed that the recovery in visual acuity is at least five times faster than expected from typical occlusion therapy in childhood amblyopia.

In the same line, Dr. Indu Vedamurthy and his colleagues [69] explore the connection between reduced suppression and improved visual function following treatment in adult amblyopia. The authors gathered twenty-three adults with amblyopia, ten with anisometropia (unequal refractive error), and thirteen with strabismus. They played 40 hours of a dichoptic action video game designed to reduce suppression, promote fusion, and increase attention by the amblyopic eye under binocular conditions. Contrary to the investigation above, the results showed no significant correlation between decreased suppression and improved visual function. This finding challenged the prevailing view and suggested that while dichoptic training improves visual acuity and stereopsis in adult amblyopia, reduced suppression is unlikely to be at the root of visual recovery. The same authors [70] also present the evaluation of a dichoptic action video game especially designed to improve amblyopia in adults. Thirty-eight adults with unilateral amblyopia participated. The experimental intervention was compared to a conventional method of supervised occlusion while watching movies. Results showed that the game group's visual acuity improved, on average, $28 \%$ more than in the movie group.
Some researchers have explored the use of serious games to train visually impaired people in different skills. For example, a short paper by [71] presents some games for learning to use the EyeCane device. EyeCane expands the traditional WhiteCane functionalities with distances and angles. Also, following the same research line, [72] present and test CPRforBlind, a video game prototype composed of 13 mini-games. Researchers designed it to introduce the main steps of the cardiopulmonary resuscitation protocol to visually impaired people. The player acts as a helper who has to save the victim by using tactile interaction to solve the challenges assigned to each mini-game. Sixteen participants ( 8 blind and 8 sighted) tested the game. The authors claim a significant improvement in CPR knowledge after playing the game; besides, blind participants found it fun and easy to play.

A similar approach is taken by [73] who present the design and developing process of AudioLink, a role-playing video game for learning scientific concepts and reasoning only through audio. Besides, they evaluated its usability and cognitive impact with 20 students (13 of them with low vision). Results indicated that users considered the software appealing, challenging, engaging, and encouraging as a science learning tool. Besides, subjects rated the usability of AudioLink highly.

Other authors [74] opt for a more analytical perspective, and propose applying a combined method for evaluating accessibility in educational video games, taking into account the Web Content Accessibility Guidelines (WCAG) 2.1. The authors evaluated 82 video games and reached the conclusion that no serious games among those selected have reached an acceptable level of accessibility. Therefore, serious game developers should make significant efforts to improve accessibility in the future.

A systematic literature review by these same authors [75] highlights current trends and prominent issues in accessibility and provides guidelines for designing serious inclusive games. The study is based on the results of existing studies published between 2000 and 2020. The authors extract a total of 476 studies, and after a screening process with the help of the PRISMA flowchart, focus on only 47 of them. The authors conclude that developers rely on assistive technologies (both software and hardware) to achieve greater accessibility in serious games. Besides, they highlight the need for research on accessibility policies, guidelines, and practices for serious games, and reflect on the threats of not taking these measures into account.

\section{NAVigation and Interaction of Visually Impaired} Players in Virtual EnVironments

Virtual environments present numerous issues to visually impaired or blind people. That may well be the reason why this subject has attracted so much attention among the scientific community researching accessibility. We will start delving into this subject by summarising some studies on different navigational strategies, used either in virtual environments or in the real world.

Teaching navigational strategies to people with vision issues has caught the attention of the scientific community. This fact should not be surprising since there are medical studies [76] that find neural correlations while blind subjects navigate virtual environments, or experiments [77] to determine the neural mechanisms underlying spatial navigation in congenitally blind individuals. The act of comparing between sighted and non-sighted people has been a recurrent theme in medical studies, and is also present in studies involving specific technology. This is the case of [78], who introduced the concept of path integration. Path integration is form of navigation in which perceived self-motion is integrated over time to obtain an estimate of current position and orientation. In their study, non- 
sighted subjects, who were passively guided over the outbound path, made significant mistakes when attempting to return to the original position, but were nevertheless sensitive to turns and segment lengths in the stimulus path. Previous research by these authors had shown that optic flow constitutes a weak input to the path integration process.

Some researches focus on creating technologies that help people perceive objects around them. For example, VizWiz::LocateIt [79] is a mobile system that enables blind people to locate objects in their environment by combining remote human computation and local automatic computer vision. The authors claim this application to be ground-breaking when solving many useful problems for blind people by changing the paradigm of search problems. It is inspired by how blind people overcome many accessibility issues today by asking a sighted person: the application first asks people to outline the object, and then enables efficient and accurate automatic computer vision to guide users in an interactive manner. Only a commercial smartphone is needed for this to work. Finally, the authors present a two-stage algorithm which aims to guide users to the object they were looking for.

Virtual environments are remarkable tools when it comes to teaching and developing orientation. Merabet and Sánchez [80] describe a series of interactive audio-based computer software and virtual environments designed to serve as rehabilitative approaches to improve spatial navigation, problem-solving skills, and overall confidence in individuals with visual impairments. The authors find substantial differences in behavioral gains obtained through virtual navigation, especially when compared to navigating the real world. Even so, they advocate for a mixed strategy, instead of replacing current rehabilitative techniques. Finally, they highlight the importance of understanding how the brain creates spatial cognitive maps as a function of learning modality and over time in order to improve rehabilitation techniques. Dr. Merabet et al. also created the Audiobased Environment Simulator (AbES) [81], a novel approach to train navigation and spatial cognition skills in adolescents who are blind within a virtual reality application. In this paper, two experiments developed with said tool are presented, involving seventeen early blind persons. The authors conclude that the application significantly encouraged blind users to explore the virtual environment actively. Besides, it generated a definite sense of large-scale three-dimensional space and facilitated learning and transferring navigational skills to the physical world.

Subsequently, [82] present an experiment with AbES in which the authors measured the ability and efficacy of adolescents with earlyonset blindness when acquiring spatial information gained from the exploration of a virtual indoor environment. Success in the transfer of navigation skill performance was markedly high, suggesting that interacting with AbES leads to the generation of an accurate spatial mental representation. Furthermore, there was a positive correlation between success in gameplay and navigation task performance. Finally, these same authors [83] delve further into the AbES as a way to explore the layout of an unfamiliar, complex indoor environment. The researchers carried out an experiment during which they compared two modes of interaction with AbES. In one group, blind participants implicitly learned the layout of a target environment while playing an exploratory, goal-directed video game. A second group was explicitly taught the same layout following a standard route and instructions provided by a sighted facilitator. Additionally, a control group interacted with AbES while playing the same kind of game. Results showed that participants from both modes of interaction were able to transfer spatial knowledge gained during gameplay. This transfer was not present in the control group.

In a previous study, [84] used a virtual environment to achieve a twofold objective: discovering the structural components and relationships that participants included in their cognitive map, and knowing how the constructed cognitive map contributes to orientation when navigating a limited space in the real-world. The author focused on the ability to recall and perform orientation tasks using long-term memory, and included a long-term experiment involving 4 participants ( 1 congenitally and 3 late blind). A point to highlight of the study is that participants were able to recall general properties of a virtual room which they visited twice, 16 months apart.

When dealing with visually impaired users, usability and accessibility while navigating are key factors to decide whether an application is worth it or not. In this regard, Jaime Sánchez has led many studies. The first one [85] presented a usability evaluation study of a haptic device designed ad hoc (Digital Clock Carpet), and a 3D video game (MOVA3D), which is based on audio in order to allow for the development of orientation and mobility skills in children when walking through closed and unfamiliar spaces. The results of this study showed that both the haptic device and the videogame were usable. The authors also described in detail the evaluation process, the re-design of some parts of the tool, and the final end-user usability evaluation. In the second one, [86] presented a design, development, and usability evaluation for the already-mentioned Audio-Based Environments Simulator (AbES) software. The environment this software creates, in this case, is a virtual representation of a real space, developed using user-centered design methodologies. As in the first study, mentioned above, results showed that users feel satisfied with the proposed interface. Researchers claimed that they are also using these simulators to study brain changes and adaptations by incorporating AbES within a neuroimaging environment.

In a previous study, the same author [87] presented, together with other colleagues, the design and usability evaluation of threedimensional interactive environments for children with visual disabilities: AudioChile and AudioVida. 3D audio aims to orient players, avoid obstacles, and identify the position of characters and objects within the environment. The authors also described the process of testing with children with residual vision and improving their graphical user interfaces. Finally, they concluded that the use of this software allows children to differentiate and identify surrounding sounds that helped them to orient themselves. Finally, Sánchez [88] also researched the problems encountered when implementing awareness in collaborative software for blind people. The study had three phases: the design of a collaborative application for learning musical instruments; the usability testing of this software with five learners who evaluate the interfaces for both interaction and collaboration; and the identification of some unique problems in implementing awareness in collaborative software for blind learners. The most important conclusion was that awareness mechanisms for people with disabilities imply more complex problems that must be considered when designing collaborative software.

Other studies present experiments designed to determine the efficiency of virtual environments to help in navigation. [89] carried out an experiment to determine the efficiency of auditory and visual cues to find gates in a game-like experience. The authors conclude that audio-visual navigation was the most efficient, followed by visual navigation, and audio-only navigation revealed itself as the least effective method. The importance of auditory stimuli in virtual reality applications is, however, highlighted, as in this scenario many essential features of the virtual environment are located outside the main field of view.

Besides, Lahav and Mioduser [90] presented and experiment, involving 31 blind participants, to prove the effectiveness of a virtual environment as a helper for visually impaired people who navigate the real world. By using haptic and audio feedback in order to ease the task of exploring unknown spaces, they examined the ability of all participants to apply cognitive maps created in a virtual environment 
when accomplishing tasks in the real world. The results attained suggest that working within the virtual environment gave participants a stimulating, comprehensive, and thorough acquaintance with the target space. Evidence of a transfer from the exploration within the virtual environment to the cognitive map built in subjects' minds is also provided. In the same vein, Wersényi [91] used a virtual environment to help the blind community to use personal computers. The author focused on technical and hearing-related questions, as well as human factors. He conducted an experiment to compare the performance of twenty eight blind users to 40 sighted subjects in a virtual auditory environment.

Auditory environments have also been tested as helpers to visually impaired people. [78] collected a series of studies on auditory distance perception in outdoor environments. These show a systematic underestimation of sound source distance. As a conclusion, the authors describe a navigation system for the visually impaired that uses three recent technologies: the Global Positioning System (GPS), Geographic Information Systems (GIS), and virtual acoustics. They also state that these three technologies show a potential to help visually impaired individuals to navigate and learn about unfamiliar environments without the assistance of human helpers.

In order to evaluate three different auditory environments, other authors [92] presented an experiment, undertaken by 8 visually impaired users (a similar, previous study with 25 sighted participants is also described in this work). The main conclusion is that sound can help both sighted and visually impaired users in 3D applications (sighted users prefer music, while visually impaired users prefer simple tones). Also, they argue that, while sound-only applications are possible for both groups, visually impaired users are more proficient while using them.

In auditory environments, there are different sonification techniques. The most known include: auditory icons (brief sounds representing objects, functions, and actions), earcons (abstract, synthetic and mostly musical tones or sound patterns that can be used in structured combinations) and speech (a voice announcing the name of the object). On the other hand, other newer techniques include a combination of the ones described above, such as spearcons (spoken phrases sped up until they may no longer be recognized as speech) and hybrids (a combination of different sound types). Dingler et al. [93] present an experiment to determine the degree of learnability for different sonification techniques aiming to represent standard environmental features. Participants were 39 undergraduate students who reported normal or corrected-to-normal hearing and vision. Authors conclude that spearcons are comparable to speech, at least regarding learnability. Also, they leave the speech channel open and are very brief, which reinforces their potential as a sonification methodology.

Following the same line, some authors [94] use spatialised sound to help blind learners to construct cognitive spatial structures. This short paper presents the design process of an interactive software. The authors also claim to have conducted experimental studies in two different Chilean schools for blind children, which included thirty learners, for two years. They researched exposure to acoustic environments, corporal exercises, and experiences with sand, clay, styrofoam, and Lego bricks. The results of these studies revealed that blind children can build mental structures only with sound and that spatial imagery is not purely visual by nature, but can be constructed and transferred through spatialised audio.

A very different and original approach is taken by [95], who present a computer application, the Audio Abacus, designed to help users navigate sequences of numbers by transforming them into tones, following the analogy of an abacus. At the time of the paper, authors declared to be in the middle of an ongoing process, during which several parameters of the application will be evaluated. Thus, they presented early results from an initial experiment, which showed that users were able to perform relatively well with this system. However, we want to point out that no later related research has been found.

It seems clear that sounds represent a basic tool to help visually impaired users to navigate virtual or real environments. A study by [96] delves into automatically generating impact sounds, based on a physical modelling method. The kind of modelling presented in this article can facilitate the implementation of non-speech auditory cues representing objects and interactions in non-visual interfaces. Also, the authors discuss the results of comparing recorded impact sounds with their abstract representations. Finally, they claim to be able to automatically generate sounds for "spherical objects falling onto a beam or plate" with fast algorithms that implement the described physical models. In spite of the promising results, no more recent work on the subject has been found.

Video games have also proven useful when comparing navigational skills between sighted and non-sighted people. [97] present a study to compare the navigational strategies that sighted and blind subjects tend to use while playing. This work is based on studies on navigation that show spatial mental models are encoded differently across both groups of players. Whereas sighted players experience higher immersion in the allocentric system (that is: they tend to view the environment as a general representation), blind players experience higher immersion in the egocentric system. The experiment was passed to 6 blind and 6 sighted players, and used a text-based video game. Results support the hypothesis that egocentric directions are more natural to use and more immersive for non-sighted players, while sighted players perform better with allocentric directions.

This whole section has made evident that audio is the most common communication channel when creating accessible navigation systems or interfaces for the blind and visually impaired. Due to the amount of work in this area, in 2015, [98] conducted a systematic review of navigational audio-based games. The authors took conceptual and technological approaches, and also gave special attention to accessibility, as well as to user interaction efficiency. A series of audio games and virtual environments are presented; they are designed to help visually impaired people to improve their ability while performing exploration and orientation tasks. They are also aimed towards helping to develop spatial navigation and problemsolving skills. Two important conclusions were reached: on one hand, audio games represent an effective means toward progression in spatial contextual learning for visually impaired people; on the other, the challenging nature of audio games promotes a high level of engagement, immersion, and active user interaction for both sighted and visually impaired people.

Additionally, it is possible to find different examples that show the benefits of audio games when addressing navigational problems. Recently, [99] presented an audio game designed to teach blind children navigation skills. It consists of a 3D exploration game, which uses a head-mounted display and a realistic soundscape to create an immersive experience. Besides, a qualitative experiment was performed in a small group of blind teenagers. The authors informed that their reactions were quite positive, making the experience engaging and fun. Finally, the authors agree on the advantages of incorporating this game into educative programs for blind people.

A different short paper [100] presented an improvement for an already existent application (it is worth mentioning that no further information on that application was found) : NAVI (Navigation Aid for Visually Impaired). The authors created this system in 2001 and improved the tool through the process that is described in this paper. 
The improvements made in NAVI are discussed, and a preliminary experimental approach is also described. This experiment focuses on developing a navigational aid for the blind through the transformation of stereo image to stereo sound.

Sound also presents advantages when interacting with mobile phones. In 2008, [101] published a study about designing nonvisual games for phones. An example called The Audio Flashlight was provided. The interface of this video game is based on audio, vibrations, and gestural input. The authors tried to avoid auditory overloading by representing collisions through touch. A preliminary evaluation indicated that players enjoyed the experience, as it seemed fun and unusual to them, especially when compared to traditional games. These authors also include an interesting discussion on the difficulties that blind people have when playing games of this type. [102] also present a study about developing an application for mobile devices, especially aimed towards people with special needs such as the blind and visually impaired.

Command-based interfaces for virtual worlds can also ease the access of visually impaired users to video games. This is the case of TextSL, a client for Second Life that can be accessed with a screen reader. The authors [103] conducted an experiment involving 16 participants ( 8 were using a screen reader and 8 were sighted) to prove its effectiveness. They concluded that a command-based interface is a feasible approach to explore Second Life, communicate with other avatars, and interact with objects. However, command-based exploration and object interaction are significantly slower in TextSL. Two significant problems were identified in the conclusions: on the one hand, objects in virtual worlds such as Second Life often lack metadata, which makes it challenging to provide an accurate textual description; on the other, virtual worlds have large numbers of objects that may easily overwhelm a user when turned into audio feedback.

While command-based interfaces seem to be an interesting way to improve accessibility, there are studies [104] on neuroscience that propose the use of technology to expand human perception and to gain a deeper understanding of brain plasticity and cognitive processes. The authors of this research review current tools for different kinds of sensory substitution. Finally, they conclude by pointing out the need for robust and cheap technology for patients suffering from any kind of sensory loss. This study supports further research on the usefulness of tactile (haptic) devices. These devices have raised a lot of expectations amongst the scientific community due to their potential for non-sighted users.

[105] make use of a haptic device in order to develop a technique called real-time sensory substitution (RTSS). It allows players who are blind to play gesture-based video games without having to make any modifications to the game itself. RTSS uses real-time video analysis to detect the presence of a particular visual cue, which is then substituted with a vibrotactile cue that is provided by an external controller. The authors also detailed a study taken by 28 sighted subjects playing Kinect Hurdles. Results found no significant difference in performance (taking into account accuracy and completion time) when interchanging visual and haptic cues in versions of the game which already make use of a semantic sound system.

Haptic technologies are also applicable to traditional games. A good example is the implementation of an accessible Sudoku by [106]. The authors expose the benefits of using a planar, touch-sensitive and refreshable haptic display and compare it with other means of interaction with blind people.

By combining haptic and audio devices, [107] present and test the GRAB project. It included a haptics and audio system provided with a set of utilities and applications which granted visually impaired people access to 3D graphics. The project included audio synthesis, speech recognition, and haptic interaction to allow for object exploration and manipulation. To validate this system, the authors tested it with an adventure game, a city map explorer, and a chart data explorer. Participants in this validation process had different degrees of blindness. Authors claimed that the results confirmed the validity and potential of the GRAB system for these applications, although some features required some adjustments in order to create usable tools.

Haptic devices have also been used for other purposes. Johnson and Higginns [108] presented the building process and preliminary validation of a compact, wearable navigation device which aids visually impaired users to navigate everyday environments in realtime. Off-the-shelf components are used to create a device capable of gathering visual inputs (through webcams), extracting relevant information about the environment (where the nearest objects are in three-dimensional space), and finally translating it into a tactile signal. Authors claim that preliminary results suggest that this device is useful for object avoidance in simple environments.

[109] compiled some recommendations and guidelines for using haptic devices. These rules are grouped under the categories of "navigation", "finding objects", "understanding objects" and "haptic widgets". The author claims that these recommendations help to improve haptic program efficiency. Other authors [110] have researched potential applications of haptic feedback in virtual worlds. In order to reach that goal, they proposed a haptic-enabled version of the Second Life game client (the same tool as [103]), which includes two haptic-based input modes to help visually impaired people while navigating and exploring the virtual $3 \mathrm{D}$ environments contained in the game. Additionally, the results of an experiment with temporarily blind-folded users show that haptic-based input modalities allow to easily find and reach avatars in virtual worlds.

A different experiment conducted by Chebat et al. [111] drew bolder conclusions. They tried to determine the ability of congenitally blind participants to detect and avoid obstacles using a sensory substitution device: the tongue display unit. 16 congenitally blind and 11 sighted subjects participated in the study. Results showed that blind participants outperformed sighted ones when detecting and avoiding obstacles using the substitution device. Besides, they demonstrated that bigger obstacles were better detected than smaller ones, and that step-around obstacles were more avoidable than step-over ones. Finally, the authors claimed to have produced the first study to show that congenitally blind participants outperform sighted ones in spatial tasks when equipped with a sensory substitution device.

Finally, [112] present a short paper including an experiment where 6 visually-impaired students evaluate a website. 4 of them were blind, and 2 had low vision. The conclusion they reach is that TAP (Think Aloud Protocol), in its simplified form as a concurrent verbal protocol method, may not be effective when applied to scenarios where blind people use a screen reader to access websites. Besides, they observed that blind users did not offer as many comments as users with low vision, even when prompted regularly. Finally, they claim that the TAP protocol should be modified in order to better adapt it to blind users.

\section{Discussion}

Analysing thematic variations of published research in accessibility and video games provides essential information on how the area of knowledge has evolved over the last 27 years. Fig. 3 illustrates the evolution in the number of published works (classified by theme) over the period considered.

Navigation and interaction works were the pioneers (the first work appears in 1994) and have dominated the field until 2015. The design and architecture of video games (either by describing final products or 


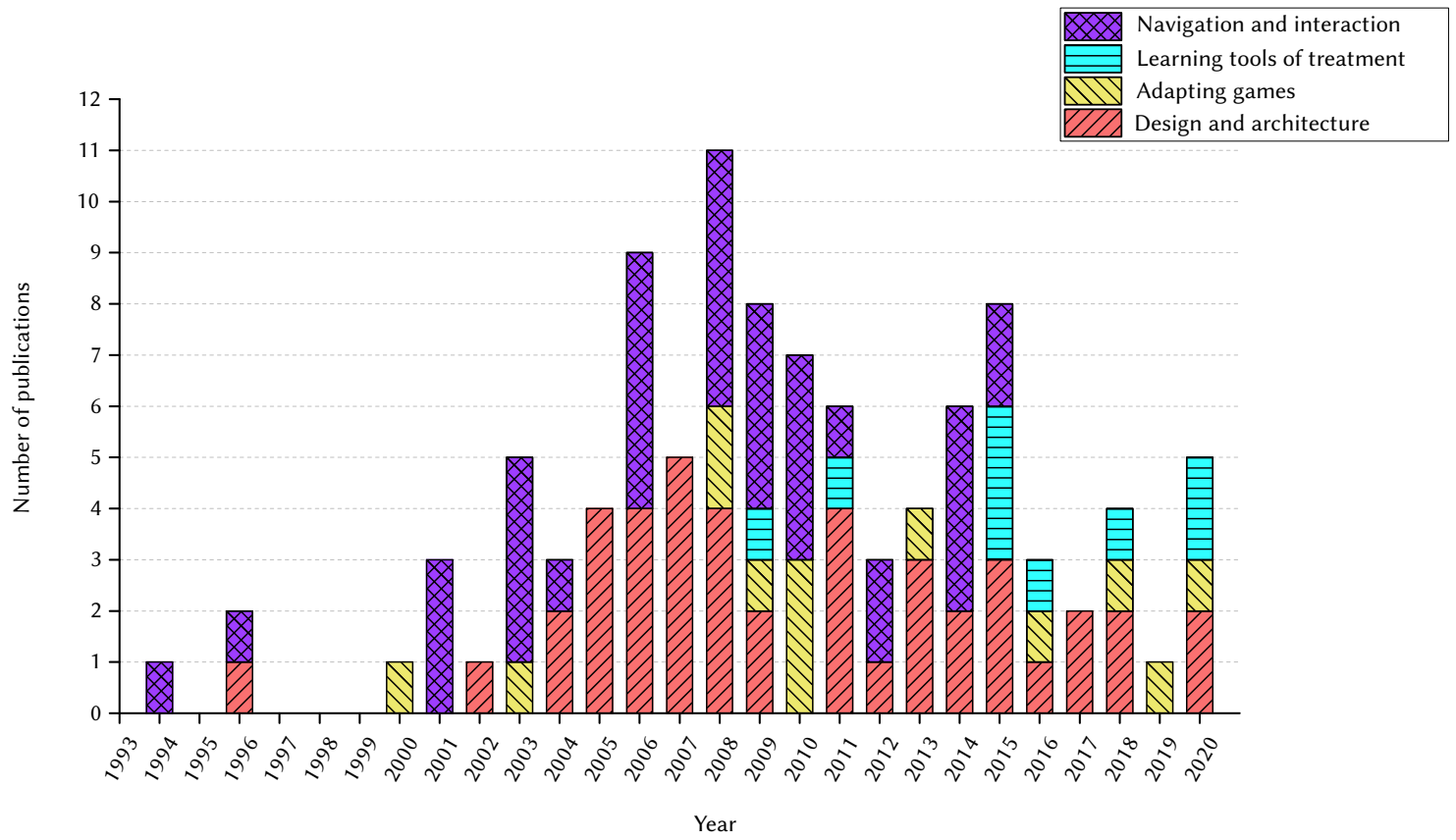

Fig. 3. Bibliography distribution over time. Bars are stacked and show the total amount of articles in this field for every year, classified by theme.

software development supporting accessible game design tasks) began to attract the researchers' interests in 2004 (the first work related to this subject was undertaken in 1996) and remains stable until today. However, academic papers that conceive video games as learning tools or treatments for the visually impaired have become far more frequent in the latest years, particularly since 2014. It seems reasonable to expect a consolidation of this tendency in the near future, as well as further growth in this field.

As for adapting games to make them more accessible, the graph shows a scarce repercussion of this subject throughout the years, and the amount of publications shows a trend to diminish. During this research process, we noticed that most authors agree that adapting video games to make them accessible is inconvenient; on the contrary, accessibility must be tackled since the beginning of the design process.

We have also detected an increment in the total number of publications on accessible entertainment since 2000. This field, however, achieved peak popularity in 2008 and, since then, the number of relevant academic papers has been reduced. The relatively low amount of recent articles found during the selection process confirms that there is still room for growth in this area.

In order to determine the trend followed by analysed papers, we included Fig. 4. It gathers the most popular keywords (catalogued and normalised to avoid repetitions) throughout the reviewed literature. Similar keywords are grouped under the same global name. For example: "video game", "video games", "games" and other similar concepts were all unified as a single term: "video-games". Additionally, keywords with only one appearance were discarded from this list to keep it relevant, as they do not allow to establish any relationship with other articles.

The first four terms in this list ("video-games", "blindness", "visual-impairment" and "accessibility") define the subject of this systematic review and are related to complementary concepts, such as "virtual-environments", "virtual-reality", "interaction", "3D", "gameengine", etc. "Sound" is the first non-thematic keyword in this list. It shows a clear trend in the field: sound is the preferred channel when implementing sensory substitution systems. Besides, it is a fundamental piece for the design and development of accessible games and interactive applications. In fact, "sound" becomes more important if we consider its tight relationship with other tangential concepts such as "audio-games", "auditory-interfaces", "spatialisation”, "soundgeneration" or "music".

"Navigation" also stands out as an essential concept; many articles reference this term in various ways. The most common approaches used to spatial navigation are related to either orienting players in virtual environments or using them to guide the real world. "Userinterface" and "human-computer-interaction" are also strictly related concepts in this field; most authors aim to create accessible interactive applications by easing the interfaces interactions. Lastly, it is also common to find articles where sensors help to make video games accessible. The "haptic" and "touch" keywords illustrate that category.

The rest of the keywords do not make enough appearances to be considered relevant enough for this analysis, and most of them act as supplementary concepts for the already-mentioned terms.

\section{Conclusions}

This paper reviews the most relevant works published in the last 27 years. The lack of very recent articles in our review can be explained by the research methods utilised - recent works have not accumulated enough citations to be well-positioned in popular academic search engines. As was already mentioned, this field has recently experienced a significant evolution, but numerous issues still need improvement. One of the main concerns amongst consulted authors is the lack of mainstream content. High-budget (AAA) titles do not usually take any accessibility measures beyond the inclusion of closed captions and are often unplayable for blind users. Additionally, most accessible products and technologies, like the ones mentioned in Section 3, are tightly related to academic environments, which reduces their social impact due to their inability to reach the general public.

After analysing this group of research articles, we detected a certain stagnation in human-computer interaction for the blind and visually impaired. Authors agree that there is a need to improve how non-visual interfaces work and develop current technologies further to adapt better to every scenario. According to the reviewed literature, the best way to improve accessibility would be to combine haptics and audio technologies to create better and more intuitive user interfaces. 


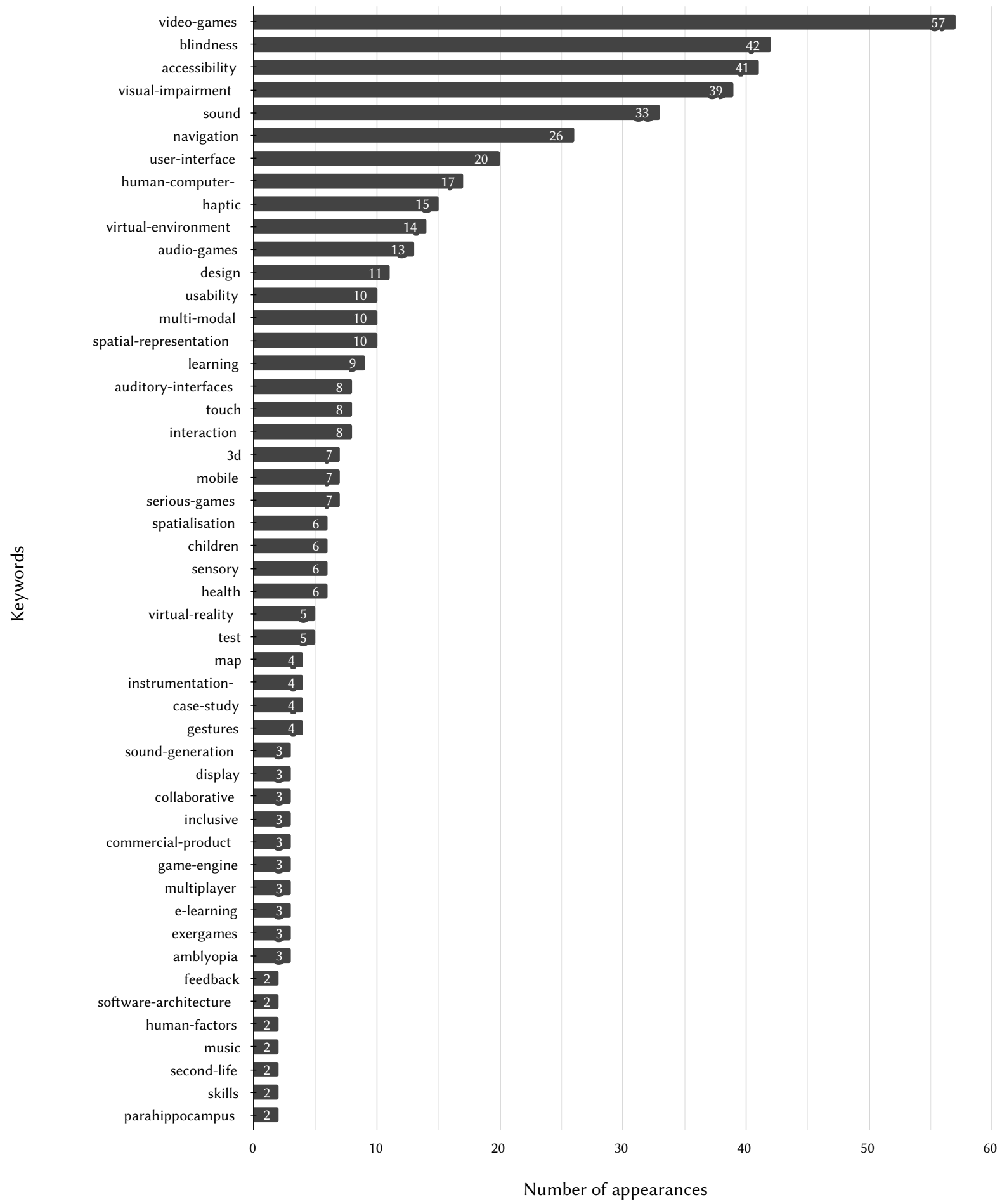

Fig. 4. Keyword distribution in reviewed literature.

This study also shows that video game development should start paying more attention to the production of accessible experiences. There is an increasing social demand, as well as a well established academic interest in this area. Still, it is also the responsibility of game creators to develop easy and intuitive ways to adapt to every manner of perceiving the world around us.

Lastly, many authors agree that there is still a long path ahead. While great companies perceive accessibility as social work (corporate social responsibility) more than a business itself, we will have two video games styles. The expensive, interesting, spectacular, and beautiful ones for the general public; and the old-fashioned, mostly dull and cheap, made to be accessible. Moreover, since accessibility must be taken into account from scratch, these two paths tend to fence off.

From our point of view, there is still much to be done before accessible video games go through academia and reach the real world, and in particular, successful, AAA projects. But a review like this one makes one thing clear: a high social demand exists, and interest in this field is growing, even among the most successful game studios. It is the role of academics to provide the world with a solid enough foundation which will allow for the development of significant games that will forever change how our societies understand computer entertainment. 
ACKNOWLEDGMENTS

This article was partially funded by a Complutense University grant (CT27/16-CT28/16) for postdoctoral research, in collaboration with Santander Bank. It has also received funding by the Ministry of Science, Innovation and Universities of Spain (Didascalias, RTI2018-096401A-I00). Additionally, this research is carried out in collaboration with the ONCE-Tiflotechnology Chair of the Complutense University of Madrid.

\section{REFERENCES}

[1] B. Leporini, F. Paternó, "Increasing usability when interacting through screen readers," Universal Access in the Information Society, vol. 3, no. 1, pp. 57-70, 2004, doi: 10.1007/s10209-003-0076-4.

[2] A. P. Freire, R. P. de Mattos Fortes, D. M. Barroso Paiva, M. A. Santos Turine, "Using screen readers to reinforce web accessibility education," ACM SIGCSE Bulletin, vol. 39, p. 82, jun 2007, doi: 10.1145/1269900.1268810.

[3] J. Lazar, A. Allen, J. Kleinman, C. Malarkey, "What frustrates screen reader users on the Web: A study of 100 blind users," International fournal of Human-Computer Interaction, vol. 22, no. 3, pp. 247-269, 2007, doi: 10.1080/10447310709336964.

[4] Y. Borodin, J. P. Bigham, G. Dausch, I. V. Ramakrishnan, "More than meets the eye: A survey of screen-reader browsing strategies," in Proceedings of the International Cross Disciplinary Conference on Web Accessibility (W4A 2010), Raleigh, 2010, pp. 1-10.

[5] A. Bhalerao, S. Bhilare, A. Bondade, M. Shingade, "Smart Voice Assistant: A universal voice control solution for non-visual access to the Android operating system," International Research fournal of Engineering and Technology(IRJET), vol. 4, no. 1, pp. 1713-1720, 2017.

[6] P. Bose, A. Malpthak, U. Bansal, A. Harsola, "Digital assistant for the blind," in Proceedings of the 2nd International Conference for Convergence in Technology (I2CT 2017), vol. 2017, Mumbai, 2017, pp. 1250-1253.

[7] S. M. Felix, S. Kumar, A. Veeramuthu, "A Smart Personal AI Assistant for Visually Impaired People," in Proceedings of the 2nd International Conference on Trends in Electronics and Informatics (ICOEI 2018), Tirunelveli, 2018, pp. 1245-1250.

[8] A. Abdolrahmani, R. Kuber, S. M. Branham, "Siri talks at you: An empirical investigation of voice-activated personal assistant (VAPA) usage by individuals who are blind," in Proceedings of the 20th International ACM SIGACCESS Conference on Computers and Accessibility (ASSETS 2018), Galway, oct 2018, pp. 249-258, Association for Computing Machinery, Inc.

[9] S. M. Branham, A. R. M. Roy, "Reading between the guidelines: How commercial voice assistant guidelines hinder accessibility for blind users," in Proceedings of the 21st International ACM SIGACCESS Conference on Computers and Accessibility (ASSETS 2019), Pittsburgh, oct 2019, pp. 446458, Association for Computing Machinery, Inc.

[10] N. Druckmann, A. Newman, K. Margenau, E. Schatz, R. Cambier, T. McIntosh, C. Gyrling, E. Pangilinan, J. Sweeney, C. Nakata, H. Gross, G. Santaolalla, "The Last of Us: Part II," 2020.

[11] D. Archambault, D. Olivier, "How to make games for visually impaired children," in Proceedings of the 2005 ACM SIGCHI International Conference on Advances in computer entertainment technology, vol. 265, Valencia, 2005, pp. 450-453.

[12] D. Archambault, R. Ossmann, T. Gaudy, K. Miesenberger, "Computer Games and Visually Impaired People," Upgrade, vol. 8, no. 2, pp. 43-53, 2007.

[13] D. Archambault, T. Gaudy, K. Miesenberger, S. Natkin, R. Ossmann, "Towards generalised accessibility of computer games," in Proceedings of the International Conference on Technologies for E-Learning and Digital Entertainment 2008, vol. 5093, Nanjing, 2008, pp. 518-527, Springer.

[14] A. Buaud, H. Svensson, D. Archambault, D. Burger, "Multimedia games for visually impaired children," in Proceedings of the International Conference on Computers for Handicapped Persons, vol. 2398, 2002, pp. 173-180, Springer Verlag.

[15] T. Roden, I. Parberry, "Designing a narrative-based audio only 3D game engine," in Proceedings of the 2005 ACM SIGCHI International Conference on Advances in computer entertainment technology, vol. 265, Valencia, 2005, pp. 274-277, ACM.
[16] M. T. Atkinson, S. Gucukoglu, C. H. Machin, A. E. Lawrence, "Making the mainstream accessible: Redefining the game," in Proceedings of the Sandbox Symposium 2006: ACM SIGGRAPH Video Game Symposium (Sandbox 2006), Boston, 2006, pp. 21-28, Springer.

[17] S. Reardon, "Playing by ear," Science, vol. 333, no. 6051, pp. 1816-1818, 2011, doi: 10.1126/science.333.6051.1816.

[18] J. Carvalho, T. Guerreiro, L. Duarte, L. Carriço, "Audio-Based Puzzle Gaming for Blind People," in Proceedings of the Mobile Accessibility Workshop at MobileHCI, 2012.

[19] K. Bierre, J. Chetwynd, B. Ellis, D. M. Hinn, S. Ludi, T. Westin, "Game Not Over : Accessibility Issues in Video Games," in Proceedings of the 3rd International Conference on Universal Access in Human-Computer Interaction, 2005, pp. 22-27.

[20] E. Velleman, R. Van Toi, S. Huiberts, H. Verwey, "3D shooting games, multimodal games, sound games and more working examples of the future of games for the blind," International Conference on Computers for Handicapped Persons, vol. 3118, pp. 257-263, 2004, doi: 10.1007/978-3-54027817-7 39.

[21] G. R. White, G. Fitzpatrick, G. McAllister, "Toward accessible 3D virtual environments for the blind and visually impaired," in Proceedings of the 3rd International Conference on Digital Interactive Media in Entertainment and Arts (DIMEA 2008), 2008, pp. 134-141.

[22] J. Chakraborty, S. Chakraborty, J. Dehlinger, J. Hritz, "Designing video games for the blind: results of an empirical study," Universal Access in the Information Society, vol. 16, pp. 809-818, aug 2017, doi: 10.1007/s10209016-0510-z.

[23] A. Sepchat, N. Monmarché, M. Slimane, D. Archambault, "Semi automatic generator of tactile video games for visually impaired children," in Proceedings of the 2006 International Conference on Computers for Handicapped Persons, vol. 4061 LNCS, Linz, 2006, pp. 372-379, Springer.

[24] J. F. Cheiran, L. Nedel, M. S. Pimenta, "Inclusive games: A multimodal experience for blind players," in Proceedings of the Brazilian Symposium on Games and Digital Entertainment (SBGAMES), 2011, pp. 164-172.

[25] K. Drossos, N. Zormpas, A. Floros, G. Giannakopoulos, "Accessible games for blind children, empowered by binaural sound," in Proceedings of the 8th ACM International Conference on Pervasive Technologies Related to Assistive Environments, (PETRA 2015), Corfu, 2015.

[26] T. Gaudy, S. Natkin, D. Archambault, "Pyvox 2: An audio game accessible to visually impaired people playable without visual nor verbal instructions," Transactions on Edutainment, vol. 5660, no. 2, pp. 176-186, 2009, doi: 10.1007/978-3-642-03270-7_12.

[27] E. P. Flores-Garzón, L. J. Intriago-Echeverría, A. Jaramillo-Alcázar, S. Criollo-C, S. Luján-Mora, "Catch the thief: An approach to an accessible video game with unity," International fournal on Advanced Science, Engineering and Information Technology, vol. 10, no. 3, pp. 905-913, 2020, doi: 10.18517/ijaseit.10.3.10938.

[28] G. Giannakopoulos, N. A. Tatlas, V. Giannakopoulos, A. Floros, P. Katsoulis, "Accessible electronic games for blind children and young people," British fournal of Educational Technology, vol. 49, pp. 608-619, jul 2018, doi: 10.1111/bjet.12628.

[29] E. Glinert, L. Wyse, "AudiOdyssey: An accessible video game for both sighted and non-sighted gamers," in Proceedings of the Conference on Future Play (Future Play '07), Toronto, 2007, pp. 251-252, ACM.

[30] D. Grammenos, A. Savidis, Y. Georgalis, C. Stephanidis, "Access invaders: Developing a universally accessible action game," in Proceedings of the International Conference on Computers for Handicapped Persons, vol. 4061 LNCS, Linz, 2006, pp. 388-395, Springer Verlag.

[31] J. Sánchez, T. Hassler, "AudioMUD: A multiuser virtual environment for blind people," IEEE Transactions on Neural Systems and Rehabilitation Engineering, vol. 15, no. 1, pp. 16-22, 2007, doi: 10.1109/ TNSRE.2007.891404.

[32] D. Grammenos, A. Savidis, C. Stephanidis, "UA-Chess: A Universally Accessible Board Game Human-Computer Interaction View project LECTOR: Attention aware Intelligent Classroom View project," in Proceedings of the 3rd International Conference on Universal Access in Human-Computer Interaction, Las Vegas, 2005, pp. 1-10.

[33] L. R. Milne, C. L. Bennett, R. E. Ladner, "VBGhost: A Braille-based educational smartphone game for children," in Proceedings of the 15th International ACM SIGACCESS Conference on Computers and Accessibility (ASSETS 2013), New York, 2013, pp. 75-76. 
[34] L. R. Milne, C. L. Bennett, S. Azenkot, R. E. Ladner, "BraillePlay: Educational smartphone games for blind children," in Proceedings of the 16th International ACM SIGACCESS Conference on Computers and Accessibility (ASSETS'14), Rochester, 2014, pp. 137-144, ACM.

[35] J. Torrente, Á. Del Blanco, P. Moreno-Ger, I. Martínez-Ortiz, B. FernándezManjón, "Implementing accessibility in educational videogames with $<\mathrm{e}$-Adventure>," in Proceedings of the 1st ACM International Workshop on Multimedia Technologies for Distance Learning, (MTDL 2009), Beijing, 2009, pp. 57-66.

[36] A. Sepchat, S. Descarpentries, N. Monmarché, M. Slimane, "MP3 players and audio games: An alternative to portable video games console for visually impaired players," in Proceedings of the 2008 International Conference on Computers for Handicapped Persons, vol. 5105 LNCS, Linz, 2008, pp. 553-560, Springer.

[37] J. McElligott, L. Van Leeuwen, "Designing sound tools and toys for blind and visually impaired children," in Proceedings of the Conference on Interaction Design and Children (IDC 2004), jun 2004, pp. 65-72, Association for Computing Machinery, Inc.

[38] S. Nesteriuk, "Audiogames: Accessibility and Inclusion in Digital Entertainment," in Lecture Notes in Computer Science (including subseries Lecture Notes in Artificial Intelligence and Lecture Notes in Bioinformatics), vol. 10917 LNCS, 2018, pp. 338-352, Springer Verlag.

[39] T. Darin, "Towards a Methodology to Evaluate Multimodal Games for Cognition in People who are Blind," in Proceedings of the International Conference on Human-Computer Interaction, Bamberg, 2015, pp. 61-65, University of Bamberg Press.

[40] T. G. Darin, R. M. Andrade, L. B. Merabet, J. H. Sánchez, "Investigating the mode in multimodal video games: Usability issues for learners who are blind," in Proceedings of the Conference on Human Factors in Computing Systems, vol. Part F1276, Denver, 2017, pp. 2487-2495.

[41] D. Grammenos, A. Savidis, C. Stephanidis, "Unified design of universally accessible games," in Proceedings of the International Conference on Universal Access in Human-Computer Interaction, vol. 4556 LNCS, Beijing, 2007, pp. 607-616.

[42] M. J. Scott, G. Ghinea, "Promoting Game Accessibility: Experiencing an Induction on Inclusive Design Practice at the Global Games Jam," in Proceedings of the Conference on the Foundations of Digital Games, Inaugural Workshop on the Global Games fam (GGJ 2013), Chania, may 2013.

[43] B. Leporini, M. Hersh, "Games for the rehabilitation of disabled people," in Proceedings of the 4th Workshop on ICTs for improving Patients Rehabilitation Research Techniques, 2016, pp. 109-112.

[44] L. J. Lieberman, "Adapting Games, Sports and Recreation for Children and Adults who are Deaf-Blind," 1996. [Online]. Available: https:// digitalcommons.brock-port.edu/pes_facpub/111.

[45] C. Mangiron, X. Zhang, "Game Accessibility for the Blind: Current Overview and the Potential Application of Audio Description as the Way Forward," in Researching Audio Description, 2016, pp. 75-95, doi: 10.1057/978-1-137-56917-2_5.

[46] D. Miller, A. Parecki, S. A. Douglas, "Finger dance: A sound game for blind people," in Proceedings of the Ninth International ACM SIGACCESS Conference on Computers and Accessibility (ASSETS'07), 2007, pp. 253-254.

[47] M. A. Oren, C. Harding, T. Bonebright, "Evaluation of spatial abilities within a 2D auditory platform game," in Proceedings of the 10th International ACM SIGACCESS Conference on Computers and Accessibility (ASSETS'08), Halifax, 2008, pp. 235-236.

[48] J. R. Porter, "Understanding and addressing real-world accessibility issues in mainstream video games," ACM SIGACCESS Accessibility and Computing, pp. 42-45, jan 2014, doi: 10.1145/2591357.2591364.

[49] R. Raisamo, A. Hippula, S. Patomaki, E. Tuominen, V. Pasto, M. Hasu, "Testing usability of multimodal applications with visually impaired children," IEEE Multimedia, vol. 13, no. 3, pp. 70-76, 2006, doi: 10.1109/ MMUL.2006.68.

[50] L. Garber, "Game Accessibility: Enabling Everyone to Play," Computer, vol. 46, no. 6, pp. 14-18, 2013, doi: 10.1109/mc.2013.206.

[51] J. Sánchez, T. Darin, R. Andrade, "Multimodal videogames for the cognition of people who are blind: Trends and issues," in Proceedings of the International Conference on Universal Access in Human-Computer Interaction, vol. 9177, 2015, pp. 535-546.

[52] T. Westin, K. Bierre, D. Gramenos, M. Hinn, "Advances in game accessibility from 2005 to 2010," in Proceedings of the International Conference on Universal Access in Human-Computer Interaction, vol. 6766, Berlin, 2011, pp. 400-409.

[53] B. Yuan, E. Folmer, F. C. Harris, "Game accessibility: A survey," Universal Access in the Information Society, vol. 10, pp. 81-100, mar 2011, doi: 10.1007/s10209-010-0189-5.

[54] M. Brown, S. L. R. Anderson, "Designing for Disability: Evaluating the State of Accessibility Design in Video Games," Games and Culture, vol. 0, no. 0, pp. 1-17, 2020, doi: 10.1177/1555412020971500.

[55] D. C. Moffat, D. Carr, "Using audio aids to augment games to be playable for blind people," in Proceedings of the Audio Mostly Conference - A Conference on Interaction with Sound, 2008, pp. 35-42.

[56] J. Sánchez, N. Baloian, T. Hassler, U. Hoppe, "AudioBattleship: Blind learners collaboration through sound," in Proceedings of the Conference on Human Factors in Computing Systems, 2003, pp. 798-799.

[57] B. A. Smith, S. K. Nayar, "The RAD: Making racing games equivalently accessible to people who are blind," in Proceedings of the Conference on Human Factors in Computing Systems (CHI 2018), vol. April, Montréal, apr 2018, Association for Computing Machinery.

[58] R. J. Mccrindle, D. Symons, "Audio space invaders," in Proceedings of the Third International Conference on Disability, Virtual Reality and Associated Technologies (ICDVRAT 2000), Alghero, 2000, pp. 59-65.

[59] T. Allman, R. K. Dhillon, M. A. Landau, S. H. Kurniawan, "Rock Vibe: Rock Band ${ }^{\circledR}$ computer games for people with no or limited vision," in Proceedings of the 11th International ACM SIGACCESS Conference on Computers and Accessibility (ASSETS'09), Pittsburgh, 2009, pp. 51-58.

[60] B. Gasperetti, M. Milford, D. Blanchard, S. P. Yang, L. Lieberman, J. T. Foley, "Dance Dance Revolution and EyeToy Kinetic Modifications for Youths with Visual Impairments," fournal of Physical Education, Recreation \& Dance, vol. 81, pp. 15-55, apr 2010, doi: 10.1080/07303084.2010.10598459.

[61] S. Kim, K. P. Lee, T. J. Nam, "Sonic-badminton: Audio-augmented Badminton game for blind people," in Proceedings of the Conference on Human Factors in Computing Systems, vol. 07-12-May-, may 2016, pp. 1922-1929, Association for Computing Machinery.

[62] T. Morelli, J. Foley, L. Columna, L. Lieberman, E. Folmer, "VI-Tennis: A vibrotactile/audio exergame for players who are visually impaired," in Proceedings of the 5th International Conference on the Foundations of Digital Games (FDG 2010), Monterey, 2010, pp. 147-154, ACM.

[63] T. Morelli, J. Foley, E. Folmer, "VI-Bowling: A tactile spatial exergame for individuals with visual impairments," in Proceedings of the 12th International ACM SIGACCESS Conference on Computers and Accessibility (ASSETS'10), Orlando, 2010, pp. 179-186.

[64] S. Vickers, H. Istance, M. J. Heron, "Accessible Gaming for People with Physical and Cognitive Disabilities: A Framework for Dynamic Adaptation," in Proceedings of the Conference on Human Factors in Computing Systems (CHI 2013), vol. April, Paris, 2013, pp. 19-24, ACM.

[65] I. Khaliq, I. D. Torre, "A study on accessibility in games for the visually impaired," in Proceedings of the 5th EAI International Conference on Smart Objects and Technologies for Social Good, Valencia, 2019, pp. 142-148, ACM.

[66] T. Olsson, Improving Accessibility for Shooter Games. $\mathrm{PhD}$ dissertation, Chalmers University, 2020.

[67] B. Yuan, E. Folmer, "Blind Hero: Enabling Guitar Hero for the visually impaired," in Proceedings of the 10th International ACM SIGACCESS Conference on Computers and Accessibility (ASSETS'08), Halifax, 2008, pp. 169-176, ACM.

[68] R. W. Li, C. Ngo, J. Nguyen, D. M. Levi, "Video-game play induces plasticity in the visual system of adults with amblyopia," PLoS Biology, vol. 9, aug 2011, doi: 10.1371/journal.pbio.1001135.

[69] I. Vedamurthy, M. Nahum, D. Bavelier, D. M. Levi, "Mechanisms of recovery of visual function in adult amblyopia through a tailored action video game," Scientific Reports, vol. 5, no. 8482, 2015, doi: 10.1038/ srep08482.

[70] I. Vedamurthy, M. Nahum, S. J. Huang, F. Zheng, J. Bayliss,D. Bavelier, D. M. Levi, "A dichoptic custom-made action video game as a treatment for adult amblyopia," Vision Research, vol. 114, pp. 173-187, sep 2015, doi: 10.1016/j.visres.2015.04.008.

[71] S. Maidenbaum, A. Amedi, "Blind in a virtual world: Mobility-training virtual reality games for users who are blind," in Proceedings of the IEEE Virtual Reality Conference (VR 2015), 2015, pp. 341-342. 
[72] A. Rodríguez, I. Boada, S. Thió-Henestrosa, M. Sbert, "CPRforblind: A video game to introduce cardiopulmonary resuscitation protocol to blind people," British fournal of Educational Technology, vol. 49, pp. 636-645, jul 2018, doi: 10.1111/bjet.12627.

[73] J. Sánchez, M. Elías, "Science learning in blind children through audiobased games," in Engineering the User Interface: From Research to Practice, Springer London, 2009, pp. 87-102, doi: 10.1007/978-1-84800-136-7_7.

[74] L. Salvador-Ullauri, P. Acosta-Vargas, M. Gonzalez, S. Luján-Mora, "Combined method for evaluating accessibility in serious games," Applied Sciences, vol. 10, no. 18, p. 6324, 2020, doi: 10.3390/APP10186324.

[75] L. Salvador-Ullauri, P. Acosta-Vargas, S. Luján-Mora, "Web-based serious games and accessibility: A systematic literature review," Applied Sciences, vol. 10, no. 21, p. 25, 2020, doi: 10.3390/app10217859.

[76] R. Kupers, D. R. Chebat, K. H. Madsen, O. B. Paulson, M. Ptito, "Neural correlates of virtual route recognition in congenital blindness," in Proceedings of the National Academy of Sciences of the United States of America, vol. 107, 2010, pp. 12716-12721.

[77] L. Gagnon, F. C. Schneider, H. R. Siebner, O. B. Paulson, R. Kupers, M. Ptito, "Activation of the hippocampal complex during tactile maze solving in congenitally blind subjects," Neuropsychologia, vol. 50, no. 7, pp. 1663-1671, 2012, doi: 10.1016/j.neuropsychologia.2012.03.022.

[78] J. M. Loomis, R. L. Klatzky, R. G. Golledge, "Navigating without vision: Basic and applied research," Optometry and Vision Science, vol. 78, no. 5, pp. 282-289, 2001, doi: 10.1097/00006324-200105000-00011.

[79] J. P. Bigham, C. Jayant, A. Miller, B. White, T. Yeh, "VizWiz::LocateIt - Enabling blind people to locate objects in their environment," in Proceedings of the IEEE Computer Society Conference on Computer Vision and Pattern Recognition (Workshops) (CVPRW 2010), 2010, pp. 65-72.

[80] L. B. Merabet, J. Sánchez, "Audio-Based Navigation Using Virtual Environments: Combining Technology and Neuroscience," AER fournal: Research and Practice in Visual Impairment and Blindness, vol. 2, no. 3, pp. 128-137, 2009

[81] L. B. Merabet, E. C. Connors, M. A. Halko, J. Sánchez, "Teaching the Blind to Find Their Way by Playing Video Games," PLoS ONE, vol. 7, sep 2012, doi: 10.1371/journal.pone.0044958.

[82] E. C. Connors, E. R. Chrastil, J. Sánchez, L. B. Merabet, "Action video game play and transfer of navigation and spatial cognition skills in adolescents who are blind," Frontiers in Human Neuroscience, vol. 8, p. 133, 2014, doi: 10.3389/fnhum.2014.00133.

[83] E. C. Connors, E. R. Chrastil, J. Sánchez, L. B. Merabet, "Virtual environments for the transfer of navigation skills in the blind: A comparison of directed instruction vs. video game based learning approaches," Frontiers in Human Neuroscience, vol. 8, may 2014, doi: 10.3389/fnhum.2014.00223.

[84] O. Lahav, "Using virtual environment to improve spatial perception by people who are blind," Cyberpsychology and Behavior, vol. 9, no. 2, pp. 174-177, 2006, doi: 10.1089/cpb.2006.9.174.

[85] J. Sánchez, M. Sáenz, M. Ripoll, "Usability of a multimodal videogame to improve navigation skills for blind children," in Proceedings of the 11th International ACM SIGACCESS Conference on Computers and Accessibility (ASSETS'09), 2009, pp. 35-42.

[86] J. Sánchez, A. Tadres, A. Pascual-Leone, L. Merabet, "Blind children navigation through gaming and associated brain plasticity," in Proceedings of the Virtual Rehabilitation International Conference (VR 2009), Haifa, 2009, pp. 29-36.

[87] J. Sánchez, M. Sáenz, "Three-dimensional virtual environments for blind children," Cyberpsychology and Behavior, vol. 9, no. 2, pp. 200-206, 2006, doi: $10.1089 / \mathrm{cpb} .2006 .9 .200$.

[88] J. Sánchez, N. Baloian, "Issues in implementing awareness in collaborative software for blind people," in Proceedings of the International Conference on Computers for Handicapped Persons, vol. 4061 LNCS, Linz, 2006, pp. 1318-1325, Springer.

[89] M. Gröhn, T. Lokki, T. Takala, "Comparison of Auditory, Visual, and Audiovisual Navigation in a 3D Space," in Proceedings of the 2003 International Conference on Auditory Display, Boston, 2003, pp. 200-203.

[90] O. Lahav, D. Mioduser, "Haptic-feedback support for cognitive mapping of unknown spaces by people who are blind," International fournal of Human-Computer Studies, vol. 66, no. 1, pp. 23-35, 2008, doi: 10.1016/j. ijhcs.2007.08.001.

[91] G. Wersényi, "Virtual localization by blind persons," AES: fournal of the
Audio Engineering Society, vol. 60, no. 7-8, pp. 568-579, 2012.

[92] S. W. Mereu, R. Kazman, "Audio enhanced 3D interfaces for visually impaired users," in Proceedings of the ACM SIGCAPH: Computers and the Physically Handicapped, 1996, pp. 10-15, ACM.

[93] T. Dingler, J. Lindsay, B. N. Walker, "Learnability of Sound Cues for Environmental Features: Auditory Icons, Earcons, Spearcons, and Speech," in 14th International Conference on Auditory Display, 2008, pp. $1-6$.

[94] J. Sánchez, M. Lumbreras, L. Cernuzzi, "Interactive virtual acoustic environments for blind children: computing, usability, and cognition," in Extended Abstracts on Human Factors in Computing Systems (CHI 2001), Seattle, 2001, pp. 65-66.

[95] B. N. Walker, J. Lindsay, J. Godfrey, "The audio abacus: Representing numerical values with nonspeech sound for the visually impaired," ACM SIGACCESS Accessibility and Computing, p. 9, sep 2003, doi: 10.1145/1029014.1028634.

[96] A. Darvishi, V. Guggiana, E. Munteanu, H. Schauer, M. Motavalli, M. Rauterberg, "Synthesizing non-speech sound to support blind and visually impaired computer users," in Proceedings of the International Conference on Computers for Handicapped Persons, Linz, 1994, pp. 385393, Springer.

[97] K. Spiel, S. Bertel, M. Heron, "Navigation and immersion of blind players in text-based games," The Computer Games fournal, vol. 3, pp. 130-152, oct 2014, doi: 10.1007/bf03392361.

[98] O. Balan, A. Moldoveanu, F. Moldoveanu, "Navigational audio games: An effective approach toward improving spatial contextual learning for blind people," International fournal on Disability and Human Development, vol. 14, no. 2, pp. 109-118, 2015, doi: 10.1515/ijdhd-2014-0018.

[99] K. Allain, B. Dado, M. V. Gelderen, O. Hokke, M. Oliveira, R. Bidarra, N. D. Gaubitch, R. C. Hendriks, B. Kybartas, "An audio game for training navigation skills of blind children," in Proceedings of the IEEE 2nd VR Workshop on Sonic Interactions for Virtual Environments (SIVE 2015), Arles, 2015, IEEE.

[100] F. Wong, R. Nagarajan, S. Yaacob, "Application of stereovision in a navigation aid for blind people," in Proceedings of the 2003 Joint Conference of the 4th International Conference on Information, Communications and Signal Processing and 4th Pacific-Rim Conference on Multimedia, vol. 2, 2003, pp. 734-737.

[101] L. Valente, C. S. D. Souza, B. Feijó, "An exploratory study on non-visual mobile phone interfaces for games," in Proceedings of the VIII Brazilian Symposium on Human Factors in Computing Systems, Porto Alegre, 2008, pp. 31-39.

[102] E. Krajnc, J. Feiner, S. Schmidt, "User centered interaction design for mobile applications focused on visually impaired and blind people," in Proceedings of the Symposium of the Austrian HCI and Usability Engineering Group (USAB 2010), vol. 6389 LNCS, 2010, pp. 195-202.

[103] E. Folmer, B. Yuan, D. Carr, M. Sapre, "TextSL: A command-based virtual world interface for the visually impaired," in Proceedings of the 11th International ACM SIGACCESS Conference on Computers and Accessibility (ASSETS'09), Pittsburgh, 2009, pp. 59-66.

[104] P. Bach-y Rita, S. W. Kercel, "Sensory substitution and the humanmachine interface," Trends in Cognitive Sciences, vol. 7, no. 12, pp. 541546, 2003, doi: 10.1016/j.tics.2003.10.013.

[105] T. Morelli, E. Folmer, "Real-time sensory substitution to enable players who are blind to play video games using whole body gestures," Entertainment Computing, vol. 5, no. 1, pp. 83-90, 2014, doi: 10.1016/j. entcom.2013.08.003.

[106] R. Gutschmidt, M. Schiewe, F. Zinke, H. Jürgensen, "Haptic emulation of games: Haptic Sudoku for the blind," in Proceedings of the 3rd International Conference on PErvasive Technologies Related to Assistive Environments, Samos, 2010, pp. 1-8.

[107] R. Iglesias, S. Casado, T. Gutiérrez, J. I. Barbero, C. A. Avizzano, S. Marcheschi, M. Bergamasco, "Computer graphics access for blind people through a haptic and audio virtual environment," in Proceedings of the 3rd IEEE International Workshop on Haptic, Audio and Visual Environments and their Applications (HAVE 2004), 2004, pp. 13-18.

[108] L. A. Johnson, C. M. Higgins, "A navigation aid for the blind using tactilevisual sensory substitution," in Proceedings of the Annual International Conference of the IEEE Engineering in Medicine and Biology, vol. 1, 2006, pp. 6289-6292. 
[109] C. Sjöström, "Using haptics in computer interfaces for blind people," in Proceedings of the Conference on Human Factors in Computing Systems, 2001, pp. 245-246.

[110] M. De Pascale, S. Mulatto, D. Prattichizzo, "Bringing Haptics to second life for visually impaired people," in Proceedings of the International Conference on Human Haptic Sensing and Touch Enabled Computer Applications (Eurohaptics 2008), vol. 5024 LNCS, Madrid, 2008, pp. 896905.

[111] D. R. Chebat, F. C. Schneider, R. Kupers, M. Ptito, "Navigation with a sensory substitution device in congenitally blind individuals," Neuroreport, vol. 22, no. 7, pp. 342-347, 2011, doi: 10.1097/WNR.0b013e3283462def.

[112] S. Chandrashekar, D. Fels, T. Stockman, R. Benedyk, "Using think aloud protocol with blind users: A case for inclusive usability evaluation methods," in Proceedings of the Eighth International ACM SIGACCESS Conference on Computers and Accessibility (ASSETS 2006), vol. 2006, 2006, pp. 251-252.

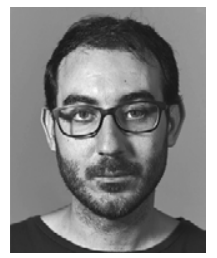

Manuel López Ibáñez

Manuel López Ibáñez is a researcher at the Department of Software Engineering and Artificial Intelligence of the Complutense University of Madrid. He holds degrees in Media Studies and Journalism from the Carlos III University (2012), a master's degree in Video Game Design (2015) from the Complutense University of Madrid, and a Ph. D in Computer Science from the same university (2019). He is also a pianist and composer, and has published three studio albums under the pseudonym of "Asomnu", as well as the soundtrack for the video game Song of Horror, by Protocol Games. Manuel has been involved in research ranging from virtual reality audio to accessible computer entertainment. He also has a keen interest in the study of sound perception, as well as in the relationship between audio and emotions. Additionally, he is the developer of LitSens: a multi-engine adaptive music generator specifically designed for first-person and virtual reality interactive experiences.

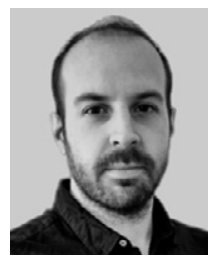

\section{Alejandro Romero-Hernández}

Alejandro Romero has a degree in Computer Engineering from the Complutense University of Madrid (UCM) and a master's degree in Digital Language Arts: Advanced Studies in Electronic Textualities from the same university (2016). Since 2015, he has been dedicated to the development of artistic video games for its application in the educational world. He is currently developing his $\mathrm{PhD}$ in Computer Engineering at the same university. His main research interest is to develop different artistical tools using new technologies as video games or different types of extended realities in order to increase the awareness of the general public to these different arts. He is currently collaborating with artistic companies such as the National Ballet of Spain, the National dance company, the royal theater of Spain, etc.

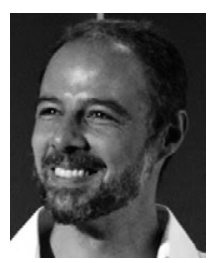

Borja Manero

Borja Manero is Associate Professor and Deputy Director of the Software Engineering and Artificial Intelligence Department, at Complutense University of Madrid. He holds a PhD in Computers Sciences and a degree in Physics, both from the Complutense University of Madrid (www.ucm.es). Besides, he studied Dramatic Arts, at Réplika Theater School of Madrid. Borja Manero is a researcher focused on the potential of the artificial intelligence and video-games to improve artistic education and communication skills. In this line, he is the director of the public speaking initiative of UCM. His involvement in different research projects funded by diverse entities (such as the Spanish Ministry for Science and Education or the European Union Framework Programme) have resulted in various articles in high impact research journals and contributions to international conferences and workshops. He also collaborated with different institutions in different countries (including a two-years scholarship at CERN, and a one-year visiting scholarship at Harvard University) resulting in a broad international experience. Finally, he co-chairs the Arts and Technology in Leadership study group at RCC/Harvard.

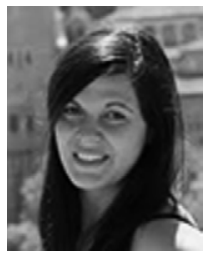

\section{María Guijarro}

María Guijarro, associate professor in the department of Computer Architecture and Automation, Faculty of Computer Science of the Complutense University of Madrid. She received a degree in Computer Engineering and a Master's degree in Computer Research. In 2009, she received a $\mathrm{PhD}$ in Computer Engineering, specialising in Artificial Intelligence, with Extraordinary PhD Prize mention. Since then, her career has focused on designing Artificial Intelligence techniques in the area of Computer Vision, e-learning, accessible technologies and machine learning. She has more than 50 scientific publications and largescale project management. 